\title{
BIOCONTROLE In Vitro De Colletotrichum siamense UTILIZANDO Trichoderma spp. E Bacillus thuringiensis var. kurstaki
}

\author{
Vinícius Spolaor Fantinel', Marlove Fátima Brião Muniz², Tales Poletto ${ }^{1}$, Adriana Falcão Dutra ${ }^{1}$, Jaqueline \\ Tomm Krahn ${ }^{3}$, Renata Fontana Favaretto 4 , Janaína Silva Sarzi ${ }^{3}$
}

\begin{abstract}
1Doutorando do Programa de Pós-Graduação em Engenheria Florestal (PPGEF) do Centro de Ciências Rurais (CCR), Universidade Federal de Santa Maria (UFSM), Av. Roraima, 1000 - - Camobi, Santa Maria - RS, 97105-900, Brasil.

2Professora Titular da Universidade Federal de Santa Maria (UFSM), Av. Roraima, 1000 - - Camobi, Santa Maria - RS, 97105-900, Brasil. ${ }^{3}$ Mestranda do Programa de Pós-Graduação em Agronomia (PPGAgro) do Centro de Ciências Rurais (CCR), Universidade Federal de Santa Maria (UFSM), Av. Roraima, 1000 - Camobi, Santa Maria - RS, 97105-900, Brasil.

${ }^{4}$ Acadêmica do Curso de Graduação em Agronomia e bolsista de Iniciação Científica PIBIC, Universidade Federal de Santa Maria (UFSM), Av. Roraima, 1000 - Camobi, Santa Maria - RS, 97105-900, Brasil.
\end{abstract}

Autor para correspondência: Vinícius Spolaor Fantinel, vinispofan@hotmail.com

\begin{abstract}
RESUMO: Acca sellowiana é uma espécie frutífera nativa da região sul do Brasil e nordeste do Uruguai, é popularmente conhecida por goiabeira-serrana, a fruta apresenta importância econômica devido ao seu alto potencial organoléptico. Pomares de goiabeira-serrana são constantemente atacados por fungos do gênero Colletotrichum, agente causal da antracnose, doença que pode levar a perdas de até $100 \%$ na produção. 0 uso de agentes biocontroladores em doenças de plantas é uma alternativa aos produtos químicos, que vêm conquistando seu espaço devido à condição de proteção e manutenção do ambiente, sendo, Trichoderma e Bacillus agentes de biocontrole em destaque. Dessa forma, o objetivo do trabalho foi avaliar a atividade antagônica in vitro de Trichoderma koningiopsis, e três produtos comerciais à base de Trichoderma spp. e um produto a base de Bacillus thuringiensis var. kurstaki para o biocontrole de Colletotrichum siamense agente causal da antracnose em goiaba-serrana. Foi realizado o pareamento de culturas, sendo avaliada a porcentagem de inibição e o potencial antagonista por escala de notas aos 6 e aos 12 dias. Aos doze dias diferiram estatisticamente da testemunha os tratamentos à base de Trichoderma spp. cujo percentual de inibição variou de 44,2\% a 39,5\%. No entanto, Bacillus thuringiensis var. kurstaki inibiu 5,1\% não diferindo significativamente em relação à testemunha. Trichoderma spp. foram eficientes no controle in vitro de C. siamense, com destaque para $T$. koningiopsis, sugerindo que esses devem ser pesquisados como agentes de controle biológico para a antracnose em goiaba-serrana.
\end{abstract}

PALAVRAS-CHAVE: goiaba-serrana, antracnose, controle biológico.

ABSTRACT: Acca sellowiana is a fruit species native to southern Brazil and northeastern Uruguay, the fruit is economically important because of its high organoleptic potential. Irrigated guava orchards are constantly attacked by fungi of the genus Colletotrichum, causal agent of anthracnose, a disease that can lead to losses of up to $75 \%$ in production. The use of biocontrol agents in plant diseases is an alternative to chemicals, they have been conquering their space due to the condition of protection and maintenance of the environment: antagonistic organisms such as Trichoderma and Bacillus are prominent as biocontrol agents. The objective of this study was to evaluate the in vitro antagonistic activity of Trichoderma koningiopsis from three commercial products based on Trichoderma spp. and a product based on Bacillus thuringiensis var. kurstaki for the biocontrol of Colletotrichum siamense causal agent of anthracnose in Acca selowiana. For this, the cultures were evaluated, the percentage of inhibition and the potential antagonist were evaluated by scale of notes at 6 and 12 days. At the 12 days, the treatments based on Trichoderma spp. whose percentage of inhibition ranged from $44,2 \%$ to $39,5 \%$. However, Bacillus thuringiensis var. kurstaki inhibited 5,1\% did not differ significantly in relation to the control. Trichoderma spp. were efficient in the in vitro control of $C$. siamense, with emphasis on $T$. koningiopsis, suggesting that these should be investigated as biological control agents for anthracnose in Acca sellowiana.

KEY WORDS: guava-mountain, anthracnose, biological control. 


\section{INTRODUÇÃO}

A goiabeira-serrana [Acca sellowiana (Berg.) Burret.], sinonímia Feijoa sellowiana Berg., da família Myrtaceae, também conhecida como "feijoa" (denominação mais utilizada na literatura internacional) e "guayabo del país" (no Uruguai), é nativa do planalto meridional brasileiro e nordeste do Uruguai. No Sul do Brasil, a espécie ocorre em condições de clima frio, com maior frequência em áreas com altitudes superiores a $800 \mathrm{~m}$ (Amarante e Santos, 2011).

A região Sul do Brasil possui várias espécies frutiferas nativas da família Myrtaceae, com potencial para a exploração comercial, das quais se destaca a goiabeira-serrana (Amarante e Santos, 2011), que vem despertando grande interesse econômico devido ao alto potencial organoléptico de seus frutos. Além do aproveitamento dos frutos, a espécie merece destaque pelas suas flores podendo ser utilizada em jardins, como planta ornamental, bem como no reflorestamento de áreas degradadas.

No entanto, a maior dificuldade na produção de mudas e frutos dessa espécie ocorre por problemas fitossanitários, sobretudo doenças fúngicas, como a antracnose causada por espécies do gênero Colletotrichum sp., causador da antracnose. A doença provoca o tombamento de plântulas, prejudicando a produção de mudas. Em plantas adultas, ocasiona a seca parcial ou total de ramos, podendo levar a planta à morte. Nos frutos, a doença causa manchas de coloração escura com centro deprimido, onde é possível visualizar as estruturas reprodutivas do patógeno formando acérvulos de coloração rósea. A doença pode danificar até $100 \%$ de frutos jovens ou próximos da maturação (Santos et al., 2011).

Devido à importância da goiabeira-serrana na economia regional e nacional (Sarmento et al., 2013), faz-se necessário a produção de mudas e frutos de boa qualidade sanitária. Para garantir isso, a melhor medida de controle de doenças de plantas é a prevenção, ou seja, aonde não há relatos de sua ocorrência, devemse tomar medidas que venham prevenir a entrada de microrganismos no local.

Outra forma de controle de doenças em plantas, haja vista que, reconhecidamente 0 uso de agrotóxicos, têm promovido diversos problemas de ordem ambiental, como a contaminação dos alimentos, do solo, da água e dos animais; a intoxicação de agricultores e a resistência de patógenos é o controle biológico através da utilização de microrganismos antagonistas (Bettiol e Ghini, 1995).

Relata-se que o custo do controle biológico é de aproximadamente um terço do controle com fungicidas (Alves et al., 2008). Desde 2009, com a liberação do uso de biocontroladores para a agricultura orgânica, pesquisas e estudos foram ampliados e contribuíram para a consolidação de processos de registros desses agentes no Brasil (Bettiol et al., 2009).

Dentre os microrganismos mais estudados para o controle biológico de doenças destacam-se espécies do gênero Trichoderma e Bacillus (Bettiol et al., 2009). Esses microrganismos são atóxicos ao homem e aos animais. De acordo com o Index Fungorum o gênero Trichoderma pertence ao Subfilo Pezizomycotina, Classe Sordariomycetes, Subclasse Hypocreomycetidae, Ordem Hypocreales, Família Hypocreacea e possuem muitas espécies que são geneticamente distintas, podendo ser encontrados no mundo todo e em praticamente todos os solos. São, ainda, fungos comercializados por algumas empresas na forma de pós-molháveis, grânulos dispersíveis, suspensões concentradas, óleos emulsionáveis, grãos colonizados e esporos secos (Morandi et al., 2009).

Diversas espécies de Bacillus são citadas como produtoras de antibióticos podendo secretar metabólitos comercialmente importantes, como enzimas aminolíticas e enzimas proteolíticas, possibilitando, dessa forma, a sua longa manutenção e sobrevivência em nichos ecológicos específicos, com grande versatilidade nos mecanismos de ação para driblar as defesas dos fitopatógenos (Bettiol e Ghini, 1995).

Diante disso, o objetivo deste trabalho foi avaliar o potencial antagônico in vitro de Trichoderma koningiopsis, três produtos comerciais a base Trichoderma spp. e um produto comercial a base de Bacillus thuringiensis var. kurstaki contra Colletotrichum siamense, patogênico à frutos de Acca sellowiana.

\section{MATERIAL E MÉTODOS}

\section{Obtenção do Patógeno}

$O$ isolado de C. siamense (SPVF1-UFSM) utilizado nos experimentos pertence ao Laboratório de Fitopatologia da Universidade Federal de Santa Maria (UFSM) - Elocy Minussi e foi isolado de frutos de goiabaserrana com sintomas de antracnose, provenientes do 
município de São Pedro do Sul (2959'32" S, 54¹0'84" W), localizado no Estado do Rio Grande do Sul.

A caracterização morfocultural, molecular e patogenicidade do isolado foi realizada por Fantinel et al. (2017), cujo código de acesso no GenBank é KX858807. O mesmo foi repicado para placas de petri contendo meio de cultura BDA e incubado à temperatura de $25 \pm 2{ }^{\circ} \mathrm{C}$, com fotoperíodo de $12 \mathrm{~h}$ por sete dias, para obtenção dos discos de meio BDA contendo estruturas do patógeno para o teste de pareamento entre culturas.

\section{Obtenção dos antagonistas}

0 isolado de Trichoderma koningiopsis foi obtido a partir da diluição de solo em um pomar de citros, cultivado em sistema orgânico de produção, situado no município de Montenegro, no Estado do Rio Grande do Sul, em estudos realizados em 2017. O mesmo está depositado na Micoteca do Laboratório de Fitopatologia da UFSM identificado como (TRICH1UFSM).

Além disso, foram utilizados três produtos comerciais à base de Trichoderma spp. e um produto a base de Bacillus thuringiensis var. kurstaki. As características de cada um estão descritas na Tabela 1. Os produtos a base de Trichoderma spp. e 0 isolado TRICH1UFSM foram inoculados em placas de petri contendo meio BDA e incubados à temperatura de $25 \pm 2$ ${ }^{\circ} \mathrm{C}$, com fotoperíodo de $12 \mathrm{~h}$ por sete dias, para obtenção dos discos contendo micélio para o teste de antagonismo.

Tabela 1. Características dos produtos comerciais de biocontrole testados contra Colletotrichum siamense.

\begin{tabular}{cccc}
\hline Produtos comerciais & Espécie & Concentração (Céls viáveis, $\mathrm{mL}^{1}$ ) & Formulação \\
\hline Quality WG $\odot$ & Trichoderma asperellum & $1 \times 10^{10}$ & Grânulos dispersíveis em água \\
Biotrich $\circledast$ & Trichoderma sp. & $1 \times 10^{9}$ & Suspensão concentrada \\
Ecotrich $\circledast$ & Trichoderma harzianum & $1 \times 10^{10}$ & Pó Molhável (WP) \\
Dipel $\odot$ & Bacillus thuringiensis var. kurstaki & $2 \times 10^{9}$ & Suspensão concentrada \\
\hline
\end{tabular}

\section{Testes de antagonismo}

Paraavaliaroantagonismodosbiocontroladores a C. siamense, utilizou-se a metodologia do teste de pareamento de culturas (Dennis e Webster, 1971). Para isso, foram utilizadas placas de Petri com $70 \mathrm{~mm}$ de diâmetro contendo meio de cultura BDA (19 g de extrato comercial de BDA (Himedia ${ }^{\circledR}$ ) para $1000 \mathrm{~mL}$ de água destilada), realizando as seguintes combinações: Trichoderma spp. x Colletotrichum siamense: um cilindro de meio de cultura BDA de $8 \mathrm{~mm}$ de diâmetro contendo micélio de $C$. siamense de sete dias, foi transferido para placas de Petri também contendo meio BDA, a aproximadamente $1 \mathrm{~cm}$ de distância da borda da placa. Esse material foi incubado durante $48 \mathrm{~h}$ a $25 \pm 2^{\circ} \mathrm{C}$, com fotoperíodo de $12 \mathrm{~h}$. Após esse período, um disco de meio de cultura BDA, com $8 \mathrm{~mm}$ de diâmetro, contendo micélio de Trichoderma spp. foi transferido para a posição oposta ao C. siamense nas placas de Petri. As placas foram incubadas durante sete dias a $25 \pm 2{ }^{\circ} \mathrm{C}$, com fotoperíodo de 12 h. As placas-controle foram compostas apenas por Trichoderma spp. e C. siamense.

Bacillus thuringiensis var. kurstaki $\mathrm{x}$ Colletotrichum siamense: um cilindro de meio de cultura BDA de $8 \mathrm{~mm}$ de diâmetro, contendo micélio de
C. siamense, foi transferido para o centro da placa de Petri, também contendo meio BDA. Esse material foi incubado durante $48 \mathrm{~h}$ a $25 \pm 2{ }^{\circ} \mathrm{C}$, com fotoperíodo de $12 \mathrm{~h}$. Posteriormente em cada quadrante da placa foi colocado $5 \mu \mathrm{L}$ de solução contendo células bacterianas de Bacillus thuringiensis var. kurstaki. As placas foram mantidas em incubadora, nas mesmas condições.

As avaliações foram realizadas pela medição do crescimento das colônias do patógeno em cada tratamento ao $6^{\circ}$ e $12^{\circ} \mathrm{dia}$, com 0 auxílio de um paquímetro digital.

A partir dos dados de crescimento micelial (mm), calculou-se a porcentagem de inibição do crescimento micelial (Menten et al., 1976), com a fórmula: \% inibição = [(crtest - crtrat) $/$ crtest $] \times 100$, em que crtest $=$ crescimento radial da testemunha; $\mathrm{e}$ crtrat = crescimento radial do tratamento. Além disso, foram atribuídas notas baseadas em escala adaptada (Bell et al., 1982), que estabelece o grau de antagonismo por meio da divisão em cinco classes de notas para diferenciação de níveis de antagonismo (notas: 1: controle total; 2: controle de 60\%; 3: controle de 40\%; 4: controle de até $20 \%$; 5 : ausência de controle).

0 delineamento estatístico foi 0 inteiramente casualizado com seis tratamentos e cinco repetições, 
sendo que no tratamento a base de Bacillus thuringiensis var. kurstaki cada repetição se constituiu pela média das quatro gotas de cada placa. Inicialmente, foi verificado se os dados apresentavam distribuição normal pelo teste de Shapiro-Wilk, utilizando o software BioEstat 5.0. Os dados que não seguiram a distribuição normal foram transformados segundo $\sqrt{ }(x+0,5)$, para a análise da variância. Os resultados em unidades decimais não sofreram transformações. A comparação das médias foi feita pelo teste de Tukey a $5 \%$ de probabilidade, utilizando-se o software SISVAR 5.3.

\section{RESULTADOS E DISCUSSÃO}

Todos os tratamentos à base de Trichoderma spp. inibiram o crescimento micelial de C. siamense, diferindo estatisticamente da testemunha tanto no sexto quanto no décimo segundo dia. Trichoderma koningiopsis, Trichoderma sp. e Trichoderma harzianum promoveram a maior porcentagem de inibição (44,2\%, $44 \%$ e $43 \%$ respectivamente) e consequentemente proporcionaram os menores valores de crescimento micelial aos doze dias $(3,4 ; 3,5$ e $3,5 \mathrm{~cm})$ (Tabela 2).

Tabela 2. Crescimento micelial e porcentagem de inibição de Colletotrichum siamense em cultivo pareado com Trichoderma spp. e Bacillus thuringiensis var. kurstaki, in vitro, aos seis e doze dias de incubação $\left(25 \pm 2{ }^{\circ} \mathrm{C}-\right.$ fotoperíodo de 12h).

\begin{tabular}{ccccc}
\hline \multirow{2}{*}{ Tratamentos } & \multicolumn{2}{c}{ Crescimento micelial $(\mathbf{c m})$} & \multicolumn{2}{c}{$\%$ Inibição } \\
\cline { 2 - 5 } & $\mathbf{6}^{\circ}$ dia & $\mathbf{1 2}^{\circ}$ dia & $\mathbf{6}^{\circ}$ dia & $\mathbf{1 2}^{\mathbf{0}}$ dia \\
\hline T. koningiopsis $\times$ C. siamense & $3,3 \mathrm{a}^{*}$ & $3,4 \mathrm{a}$ & $32 \mathrm{a}$ & $44,2 \mathrm{a}$ \\
\hline Trichoderma sp. $\times$ C. siamense & $3,3 \mathrm{a}$ & $3,5 \mathrm{a}$ & $32 \mathrm{a}$ & $44 \mathrm{a}$ \\
\hline Trichoderma asperellum $\times$ C. siamense & $3,5 \mathrm{a}$ & $3,7 \mathrm{a}$ & $28 \mathrm{~b}$ & $39,5 \mathrm{~b}$ \\
\hline Trichoderma harzianum $\times$ C. siamense & $3,4 \mathrm{a}$ & $3,5 \mathrm{a}$ & $30 \mathrm{ab}$ & $43 \mathrm{a}$ \\
\hline Bacillus thuringiensis $\times$ C. siamense & $6,1 \mathrm{~b}$ & $6,7 \mathrm{~b}$ & $1,5 \mathrm{c}$ & $5,1 \mathrm{c}$ \\
\hline Testemunha & $6,7 \mathrm{~b}$ & $7,0 \mathrm{~b}$ & $0,0 \mathrm{c}$ & $0,0 \mathrm{c}$ \\
\hline
\end{tabular}

*Médias seguidas pela mesma letra, na coluna, não diferem entre si pelo teste de Tukey a $5 \%$ de significância.

A capacidade de biocontrole de Trichoderma koningiopsis pode estar relacionada com o fato de o isolado não ter sido armazenado. Além do que, já foi relatado que isolados de Trichoderma spp. nativos são mais agressivos do que os de formulação comercial (García-Núñez et al., 2012). Também se relatou que isolados de formulação comercial apresentam redução na viabilidade tanto in vitro quanto in vivo, quando comparado com Trichoderma koningiopsis nativo no controle de Sclerotinia sclerotiorum (Da Silva et al., 2015).

Oliveira et al., (2016), na avaliação da eficiência de isolado de Trichoderma sp. no controle de Colletotrichum musae, agente causal da antracnose na cultura da bananeira, encontraram índices de inibição de $84 \%$ in vitro e $54 \%$ in vivo. Assim como, Junior Chagas et al. (2016) verificaram a eficiência do uso de 56 isolados de Trichoderma spp. no controle in vitro de Colletotrichum truncatum.

Também foi observado em estudos in vitro com culturas pareadas a inibição do crescimento micelial de Colletotrichum graminicola por isolados de Trichoderma spp., além disso, essas espécies produziram metabólitos extracelulares difusíveis que inibiram o crescimento do patógeno (Michereff et al., 1993). Da mesma maneira, estudando o potencial antagônico de quatro isolados de Trichoderma viride ( $\operatorname{Tr} 3,8,12$ e 14) contra Colletotrichum capsici, foi observada uma inibição variando entre 61,23 e 70,14\% (Mishra et al., 2011).

O gênero Trichoderma tem sido bastante estudado, devido a diversidade de mecanismos antagônicos que apresenta, entre os quais, destacamse a produção de metabólitos e de enzimas com propriedades antifúngicas, mostrando a versatilidade da ação inibitória em relação a fitopatógenos (Mesquita et al., 2017).

Amenor porcentagem de inibição de Trichoderma spp. se deu no tratamento Trichoderma asperellum $\times$ C. siamense $(39,5 \%)$ que diferiu significativamente dos demais tratamentos. Resultados também observados em teste em cultivo pareado de Trichoderma no biocontrole, in vitro, de Colletotrichum musae e Colletotrichum truncatum respectivamente (Junior Chagas et al., 2016). Da mesma forma, encontrou-se a menor porcentagem de crescimento de Dactylonectria macrodidyma quando submetido ao tratamento com Trichoderma asperellum (Santos et al., 2016). 
A menor ação antagônica pode ser resultado de uma maior competição pelos nutrientes do meio, ou uma menor produção de protease e cisteína, enzimas produzidas pelas espécies de Trichoderma que inativam a capacidade enzimática do fitopatógeno (Bomfim et al., 2010). Além do que, as espécies de Trichoderma utilizam várias estratégias para o controle desses, como a competição por nichos ecológicos e nutrientes, antibiose e o micoparasitismo, entretanto, cada espécie possui o seu próprio modo de ação para interagir com cada tipo de fitopatógeno (Ribeiro, 2017).

No tratamento em que $C$. siamense foi confrontado com Bacillus thuringiensis foi possível observar um aumento na porcentagem de inibição a partir do sexto dia após a sua inoculação, porém não diferiu significativamente do controle.

Mesmo assim, a necessidade de substituir e/ ou reduzir a utilização de produtos químicos, faz com que outros estudos nessa mesma linha de pesquisa ampliem seu espaço. Bactérias do gênero Bacillus possuem grande potencial para serem usadas como agentes de controle biológico, pois mantêm sua viabilidade quando estocadas por longos períodos (Petras e Casida, 1985).

$B$. thuringiensis é uma bactéria de solo, Grampositiva, que pode produzir cristais durante a fase de esporulação. Esses consistem em proteínas (Cry) que exibem toxicidade forte e específica contra uma variedade de insetos, como Lepidoptera, Coleoptera e Diptera, assim como, contra alguns nematóides, ácaros e protozoários (Peng et al., 2015).

Vários estudos utilizando Bacillus como agente de biocontrole de fungos fitopatogênicos foram conduzidos sendo encontrados resultados diversos. Bacillus subtillis em formulação comercial apresentou resultados significativamente inferiores no teste de pareamento quando comparado com os tratamentos utilizando Trichoderma spp. contra Dactylonectria macrodidyma (Santos et al., 2016). Utilizando as mesmas formulações, também se encontrou resultados inferiores no crescimento micelial e porcentagem de inibição de Lasiodiplodia theobromae quando comparada com Trichoderma spp. (Maciel et al., 2017).

Entretanto, também há pesquisas que demonstram que $B$. subtilis foi capaz de inibir entre 48,75 e $72,01 \%$ o crescimento micelial de Colletotrichum gloesporioides, in vitro, e entre 32 e $64 \%$ os sintomas da antracnose em pimenta, in vivo (Amaro et al., 2018). Já em outro estudo, foi observado que $B$. subtilis e $B$. thuringiensis foram eficientes no controle in vitro de C. graminicula, mas que isso não ocorreu em experimento in vivo (Jacques, 2015).

Comparando-se a ação antagonista de Trichoderma spp. e Bacillus spp. no controle de Fusarium oxysporum, observou-se que, embora ambos tenham inibido o crescimento micelial do patógeno, in vitro, os isolados de Trichoderma apresentaram percentual de inibição maior que $70 \%$, em sua maioria, enquanto que os de Bacillus não ultrapassaram 64\% (Kumar et al., 2012). Assim como, em estudo realizado sobre formas potenciais de biocontrole de Macrophomina phaseolina e Fusarium solani na cultura do morangueiro, os isolados de Trichoderma também foram mais eficazes no controle dessas doenças, em relação aos isolados de Bacillus (Pastrana et al., 2016).

Considerando através de escala (Bell et al., 1982), Trichoderma asperellum x C. siamense, diferiu da testemunha aos doze dias de avaliação com nota 3 e os tratamentos que apresentaram a melhor nota (2) ao final do experimento, foram 0 isolado nativo de Trichoderma koningiopsis; Trichoderma sp. e Trichoderma harzianum (Fig. 2), sendo esses, portanto, eficientes no controle in vitro de $C$. siamense.

Figura 1. Crescimento micelial de Colletotrichum siamense (à esquerda) em pareamento com Trichoderma spp. (à direita).

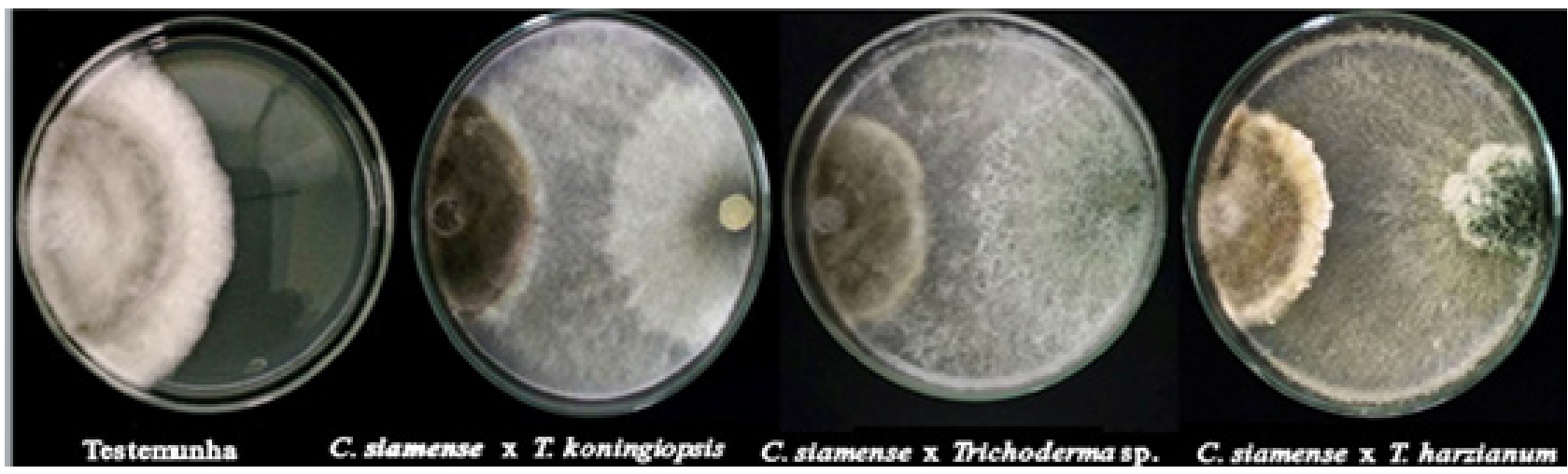


Figura 2. Notas atribuídas ao cultivo pareado de Colletotrichum siamense submetido a diferentes tratamentos (T1: Colletotrichum siamense x Trichoderma koningiopsis; T2: Colletotrichum siamense x Trichoderma sp.; T3: Colletotrichum siamense x Trichoderma asperellum; T4: Colletotrichum siamense x Trichoderma harzianum; T5: Colletotrichum siamense $\mathrm{x}$ Bacillus thuringiensis var. kurstaki; T6: Testemunha; avaliadas aos 6 e aos 12 dias após o pareamento.

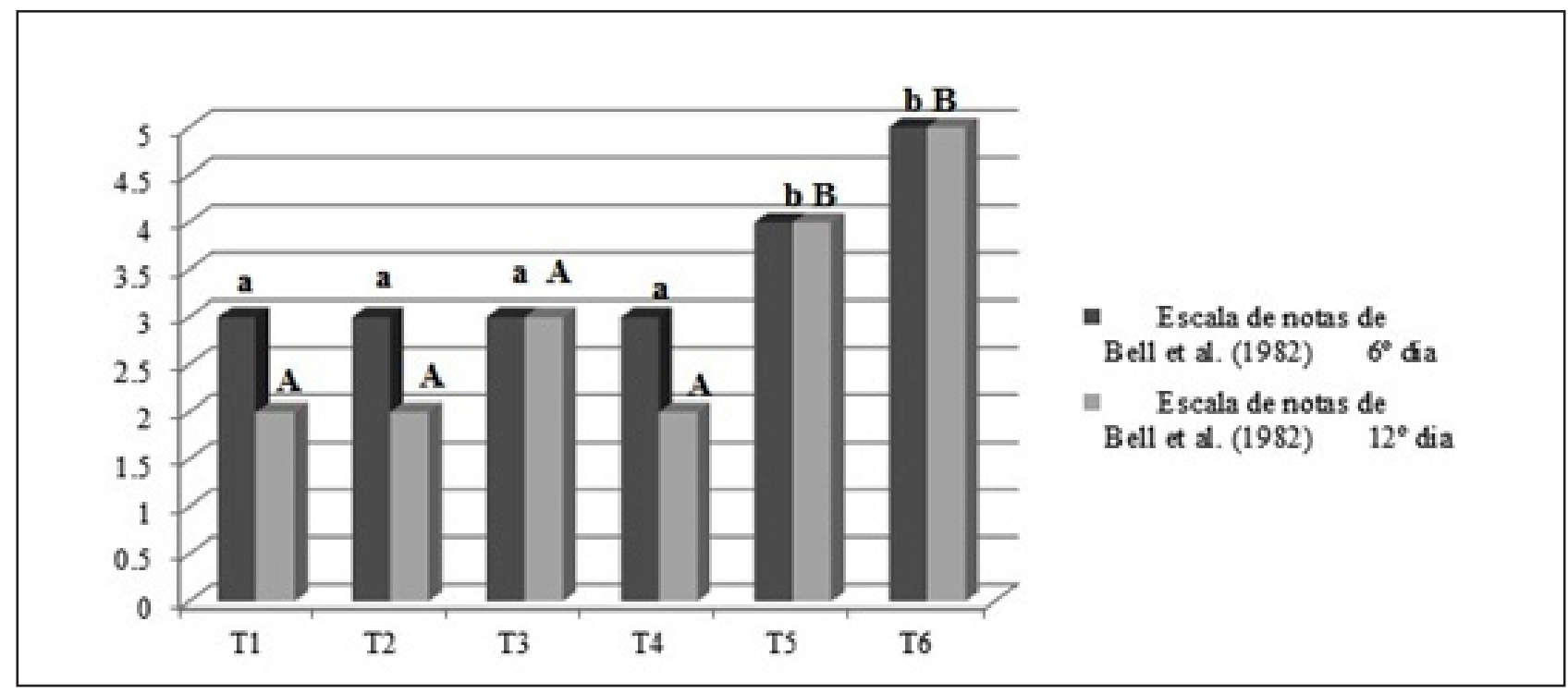

* Barras seguidas pela mesma letra minúscula aos 6 dias e maiúscula aos 12 dias de avaliação não diferem entre si pelo teste de Tukey a $5 \%$ de probabilidade.

Bacillus thuringiensis var. kurstaki $\times$ C. siamense não diferiu significativamente da testemunha no sexto $\mathrm{e}$ no décimo segundo dia, apresentando nota 4 em ambos os dias. Cabe ressaltar ainda que 0 antagonismo in vitro é uma forma utilizada apenas para seleção massal de candidatos a agentes de biocontrole, pois nem todos aqueles que apresentam efeitos inibitórios in vitro conseguem exercer o mecanismo de antagonismo in vivo, visto que algumas condições de temperatura e umidade podem interferir no desenvolvimento tanto do agente de biocontrole, quanto do patógeno (Bell et al., 1982).

Dessa maneira, Trichoderma koningiopsis (TRICH1-UFSM) e os produtos comerciais à base de Trichoderma spp. foram eficientes no controle in vitro de Colletotrichum siamense sugerindo que esses devem ser pesquisados como agentes de controle biológico para a antracnose em goiaba-serrana em estudos in vivo.

Bacillus thuringiensis var. kurstaki não se mostrou eficiente no controle de Colletotrichum siamense.

\section{AGRADECIMENTOS}

À CAPES e ao CNPQ, pelo apoio financeiro e concessão de bolsas.

\section{REFERÊNCIAS BIBLIOGRÁFICAS}

Alves, S. B.; Lopes, R. B.; Vieira, S. A.; Tamai, M. A. Fungos entomopatogênicos usados no controle de pragas na América Latina. In: Controle microbiano de pragas na América Latina: avanços e desafios; Lopes, $R$. B., Eds; FEALQ: Piracicaba, São Paulo, 2008, 69-110.

Amarante, C. V. T. Do; Santos, K. L. D. Feijoa (Acca sellowiana). Revista Brasileira de Fruticultura, 2011, 33, 1, 1-334.

Amaro, J. K. C.; Vieira, B. S.; Sousa, L. A. Biological control of Colletotrichum gloeosporioides in pepper with isolates of Bacillus subtilis. Brazilian Journal of Agriculture, 2018, 93, 2, 195-209.

Bell, D. K.; Wellls, H. D.; Markham, C. R. In vitro antagonism of Trichoderma species against six fungal plant pathogens. Phytopathology, 1982, 72, 1, 379-382.

Bettiol, W.; Ghini, R. Controle biológico. In: Manual de fitopatologia: princípios e conceitos, edição no 3; Bergamin Filho, A.; Kimati, H.; Amorin, L., Eds.; Agronômica Ceres: São Paulo, São Paulo, 1995; Vol. 2, p. 717-728. 
Bettiol, W.; Morandi, M. A. B.; Pinto, Z. V.; Paula Junior, T. J.; Corrêa, E. B.; Moura, A. B.; Lucon, C. M. M.; Costa, J. C. B.; Bezerra, J. L. Bioprotetores comerciais para o controle de doenças de plantas. Revisão Anual de Patologia de Plantas, 2009, 17, 111-147.

Bomfim, M. P.; José, A. R. S.; Rebouças, T. N. H.; Almeida, S. S. De; Souza, I. V. B.; Dias, N. O. Avaliação antagônica in vitro e in vivo de Trichoderma spp. a Rhizopus stolonifer em maracujazeiro amarelo. Summa Phytopathologica, 2010, 36, 1, 61-67.

Da Silva, G. B. P.; Heckler, L. I.; Santos, R. F. Dos; Durigon, M. R.; Blume, E. Identificação e utilização de Trichoderma spp. armazenados e nativos no biocontrole de Sclerotinia sclerotiorum. Revista Caatinga, 2015, 28, 4, 33-42.

Dennis, C.; Webster, J. Antagonistic properties of species-groups of Trichoderma. III - Hyphal interaction. Transactions of the Bristish Mycological Society, 1971, 57, 368-369.

Fantinel, V. S.; Muniz, M. F. B.; Blume, E.; Araújo, M. M.; Poletto, T.; Silva, T. T. Da; Dutra, A. F.; Maciel, C. G.; Harakava, R. First report of Colletotrichum siamense causing anthracnose on Acca sellowiana fruits in Brazil. Plant Disease, 2017, 101, 6, 1035-1035.

Garcia-Núñez, H. G. Isolation of native strains of Trichoderma spp. from horticultural soils of the Valley of Toluca, for potential biocontrol of Sclerotinia. Tropical and Subtropical Agroecosystems, 2012, 15, 2, 357-365.

Jacques, F. L. Efeito de produtos alternativos in vitro e em casa de vegetação no controle de Colletotrichum graminicola. 2015. Dissertação (Mestrado em Agronomia) - Setor de Ciências Agrárias e de Tecnologia, Universidade Estadual de Ponta Grossa, Ponta Grossa.

Junior Chagas, A. F.; Godoy, V. H. Da S.; Miller, L. De O.; Carvalho Filho, M. R. De. Bioprospecção de Trichoderma spp. sobre o crescimento micelial de Colletotrichum cliviae e C. truncatum. Revista Brasileira de Biociências, 2016, 14, 4.

Kumar, D. P.; Thenmozhi, R.; Anupama, P. D.; Nagasathya, A.; Thajuddin, N.; Paneerselvam,
A. Selection of potential antagonistic Bacillus and Trichoderma isolates from tomato rhizospheric soil against Fusarium oxysporum F. sp. Lycoperscisi. Journal of Microbiology and Biotechnology Research, 2012, 2, 1, 78-89.

Maciel, C. G.; Muniz, M. F. B.; Rolim, J. M.; Michelon, R. M. D. N.; Poletto, T.; Rabuske, J. E. Uso da microbiolização contra Lasiodiplodia theobromae em sementes de Pinus spp. Floresta, 2017, 47, 1, 121-128.

Menten, J. O. M.; Machado, C. C.; Munissi, E.; Castro, C.; Kimati, H. Efeito de alguns fungicidas no crescimento micelial de Macrophomina phaseolina (Tass) Goid, "in vitro". Fitopatologia Brasileira, 1976, 1, 57-66.

Mesquita, D. C. M.; Ferreira, F. A.; Martins, I.; Mello, S. C. M.; Carvalho, D. D. C. Antagonismo in vitro de Trichoderma spp. a Sclerotinia sclerotiorum do feijão comum. Agropecuária Científica no Semiárido, 2017, 13, 1, 1-4.

Michereff, S. J.; Menezes, M.; Mariano, R. L. R. Antagonismo de espécies de Trichoderma sobre Colletotrichum graminicola, agente da antracnose de sorgo em condições de laboratório. Summa Phytopathologica, 1993, 1, 1, 14-17.

Mishra, B. K.; Mishra, R. K.; Mishra, R. C.; Tiwari, A. K.; Yadav, R. S.; Dikshit, A. Biocontrol efficacy of Trichoderma viride isolates against fungal plant pathogens causing disease in Vigna radiata L, Arch. Journal of Applied Sciences Research, 2011, 3, 2, 361369.

Morandi, M. A. B.; Paula Júnior, T. J. De; Bettiol, W.; Teixeira, $\mathrm{H}$. Controle biológico de pragas, doenças e plantas invasoras. Informe Agropecuário, 2009, 30, 251, 73-82.

Oliveira, E. S.; Viana, F. M. P.; Martins, M. V. V. Alternativas a fungicidas sintéticos no controle da antracnose da banana. Summa Phytopathologica, 2016, 42, 4, 340-350.

Pastrana, A. M.; Basallote-ureba, M. J.; Aguado, A.; Akdi, K.; Capote, N. Biological control of strawberry soil-borne pathogens Macrophomina phaseolina and Fusarium solani, using Trichoderma asperellum and 
Bacillus spp. Phytopathologia Mediterranea, 2016, 55, 1, 109-120.

Peng, D.; Pang, C.; Wu, H.; Huang, Q.; Zheng, J.; Sun, M. The expression and crystallization of Cry65Aa require two C-termini, revealing a novel evolutionary strategy of Bacillus thuringiensis Cry proteins. Scientific Reports, 2015, 5, 1-12.

Petras, S. F.; Casida, L. E. J. Survival of Bacillus thuringiensis spores in soil. Applied and Environmental Microbiology, 1985, 50, 1496-1501.

Ribeiro, M. S. Estudo funcional do gene gluc31 que codifica uma $\beta$-1,3-glucanase da família $\mathrm{GH} 16$ de Trichoderma harzianum. 2017. Tese (Doutorado em Ciências Biológicas) - Instituto de Ciências Biológicas, Universidade Federal de Goiás, Goiânia.
Santos, K. L.; Siminski, A.; Ducroquet, J. P. H. J.; Guerra, M. P.; Peroni, N.; Nodari, R. O. Acca sellowiana. In: Espécies nativas da flora brasileira de valor econômico atual ou potencial: plantas para o futuro - Região Sul. Coradin, L.; Siminski, A.; Reis, A., Eds. MMA: Brasília, Goiás, 2011; p. 111-130.

Santos, R. F. Dos; Heckler, L. I.; Lazarotto, M.; Garrido, L. Da R.; Rego, C.; Blume, E. Trichoderma spp. and Bacillus subtilis for control of Dactylonectria macrodidyma in grapevine. Phytopathologia Mediterranea, 2016, 55, 2, 293-300.

Sarmento, M. B.; Silva, A. C. S. Da; Villela, F. A.; Santos, K. L. Dos; Mattos, L. C. P. De. Teste de tetrazólio para avaliação da qualidade fisiológica em sementes de goiabeira-serrana. Revista Brasileira de Fruticultura, 2013, 35, 1, 270-276. 